\title{
PENGGUNAAN MEDIA ONLINE DALAM LELANG PROYEK PEMBANGKIT LISTRIK TENAGA SURYA DI PULAU SEMBILAN KABUPATEN SINJAI
}

\section{Online Media in Auction of Solar Power Plant at The Pulau Sembilan District of Sinjai}

\author{
Muhammad Takdir ${ }^{1}$, Hafied Cangara ${ }^{2}$, Rhiza S. Sadjad ${ }^{3}$ \\ ${ }^{1}$ Program Studi Ilmu Komunikasi Pasca Sarjana Universitas Hasanuddin (muhammad.takdir@gmail.com) \\ ${ }^{2}$ Dosen Ilmu Komunikasi Fakultas Ilmu Sosial dan Ilmu Politik Universitas Hasanuddin \\ (hafied.cangara@unhas.ac.id) \\ ${ }^{3}$ Dosen Teknik Elektro Fakultas Teknik Universitas Hasanuddin (rhiza@unhas.ac.id)
}

\begin{abstract}
ABSTRAK
Pelaksanaan lelang PLTS di Sinjai telah berlangsung sejak tahun 2013 dan telah memberikan banyak pertanyaan tentang penggunaan media online dalam prosesnya terutama dengan adanya lelang berulang kali bahkan kasusnya sampai ke ranah hukum. Penelitian ini bertujuan untuk menggambarkan penggunaan media online serta transparansi dalam proses lelang PLTS di Pulau Sembilan Kabupaten Sinjai. Metode penelitian yang digunakan adalah kualitatif deskriptif dengan teknik pengumpulan data dilakukan melalui interview, observasi dan dokumentasi. Informan dipilih secara purposive sampling sebanyak 23 orang. Data dianalisa secara kualitatif. Hasil penelitian menunjukkan bahwa penggunaan media online merupakan suatu bagian upaya untuk mewujudkan proses pengadaan barang dan jasa pemerintah yang lebih efisien dan transparan sesuai visi dan misi Kabupaten Sinjai, walau belum sepenuhnya bias mendukung open government dan open data. Kendala yang dihadapi adalah keterbatasan infrastruktur seperti ruangan khusus untuk server, gangguan koneksi internet yang sering terjadi, serta sistem yang digunakan sepenuhnya belum bisa memberikan informasi secara mendetail tentang proses lelang yang dilakukan. Untuk itu penelitian ini menyarankan agar tempat untuk server ditata dengan baik dari aspek keamanan dan aksesibilitas, meminimalisasi gangguan jaringan, dan terus mengupdate sistem lelang secara online sehingga penentuan pemenang lelang selanjutnya lebih terbuka.
\end{abstract}

Kata Kunci : Transparansi, Open Government, Open Data

\section{ABSTRACT}

PLTS in Sinjai auction has been going on since 2013 and has provided a lot of questions about the use of online media in the process, especially with the auction repeatedly even the case came into law. This study aimed to describe the use of online media as well as transparency in the auction process PLTS in Pulau Sembilan Sinjai. The method used is descriptive qualitative techniques of data collection is done through interview, observation and documentation. Informants selected by purposive sampling as many as 23 people. Data were analyzed qualitatively. The results showed that the use of online media is a part of efforts to realize the process of government procurement more efficient and transparent according to the vision and mission of Sinjai, though not yet fully able to support open government and open data. The challenge remains the lack of infrastructure such as special rooms for the server, Internet connection disruption is often the case, as well as the systems used can not fully provide detailed information about the auction process. Therefore this study suggest that a server is well laid out from the aspect of security and accessibility, minimizing network disruption, and keep updating online auction system so that determining the winner of the next auction is open.

Keywords: Transparency, Open Government, Open Data

\section{PENDAHULUAN}

Keterbukaan atau transparansi berarti keterbukaan pemerintah dalam memberikan informasi yang terkait dengan aktivitas pengelolaan sumber daya publik kepada pihak- pihak yang membutuhkan informasi (Mardiasmo, 2004).

Prinsip keterbukaan dalam UU No. 14 Th. 2008 menghendaki agar penyelenggaraan pemerintahan dilaksanakan secara terbuka atau 
transparan, yaitu bahwa berbagai kebijakan dalam penyelenggaraan pemerintahan harus jelas, tidak dilakukan secara sembunyisembunyi dan rahasia, tetapi segala sesuatunya baik perencanaan dan pertanggungjawabannya dapat diketahui oleh publik terkecuali untuk informasi yang memang bersifat terbatas dan ketat maka pemerintah dapat memberikan batasan ketika informasi tersebut diakses .

Menurut Rogers dalam Abrar (2003), merangkumkan perkembangan media komunikasi ke dalam empat era. Pertama, era komunikasi tulisan, Kedua, era komunikasi cetak, Ketiga, era telekomunikasi, dan Keempat, era komunikasi interaktif. Media baru adalah media yang berkembang pada era komunikasi interaktif. Ron Rice mendefinisikan media baru adalah media teknologi komunikasi yang melibatkan komputer di dalamnya (baik mainframe, PC maupun Notebook) yang memfasilitasi penggunanya untuk berinteraksi antar sesama pengguna ataupun dengan informasi yang diinginkan. Sementara menurut McQuail, media baru adalah tempat dimana seluruh pesan komunikasi terdesentralisasi; distribusi pesan lewat satelite meningkatkan penggunaan jaringan kabel dan komputer, keterlibatan audiens dalam proses komunikasi yang semakin meningkat.

Pemerintah sebagai penyelenggara negara penyedia layanan publik tentu tidak boleh tertinggal dengan perkembangan internet yang semakin pesat ini dan harus segera memanfaatkannya agar pelayanan yang diberikan bisa semakin baik dan terjaga kualitasnya.

Salah satu langkah yang telah dilakukan oleh pemerintah di Indonesia adalah dengan tersedianya website (situs elektronik) pemerintah hingga tingkat kabupaten kota yang memberikan informasi-informasi terkini tentang daerah tersebut termasuk dengan promosi-promosi sumber daya daerah. Website dari sebuah lembaga publik, adalah merupakan salah satu jendela utama bagi terciptanya keterbukaan informasi.

Salah satu langkah yang perlu dilakukan oleh pemerintah untuk membuka keran keterbukaan ini adalah dengan membuka informasi pelaksanaan tender-tender proyek kepada publik agar memberikan kesempatan seluasnya pada siapa saja yang memiliki kompetensi untuk ikut terlibat dalam pekerjaan yang ditawarkan dan juga bisa ikut mengawasi jalannya pekerjaan.

Listrik di kecamatan Pulau Sembilan telah menjadi salah satu kebutuhan yang sulit untuk dipenuhi karena PLN belum menyediakan transmisi listrik bawah laut di Sinjai. Untuk mengantisipasinya maka pemerintah Kabupaten Sinjai melalui Dinas Pertambangan dan Energi melakukan survey dan melihat bahwa panas matahari di Pulau Sembilan sangat cocok untuk pembangkitan tenaga listrik.

Saat ini, listrik yang ada di Pulau Sembilan dari swadaya masyarakat dan iuran bulanan yang menyediakan genset bersama. Rata-rata listrik hanya menyala pukul 18.00 hingga pukul 22.00. Saat siang tidak ada listrik sama sekali di rumah warga.

Listrik di kecamatan Pulau Sembilan telah menjadi salah satu kebutuhan yang sulit untuk dipenuhi karena PLN belum menyediakan transmisi listrik bawah laut di Sinjai. Untuk mengantisipasinya maka pemerintah Kabupaten Sinjai melalui Dinas Pertambangan dan Energi melakukan survey dan melihat bahwa panas matahari di Pulau Sembilan sangat cocok untuk pembangkitan tenaga listrik.

Kebutuhan akan listrik ini telah disuarakan oleh masyarakat melalui Musyawarah Perencanaan Pembanguan (musrenbang) dari tingkat kecamatan hingga kabupaten. Hasilnya adalah dibukanya tender untuk pengadaan Pembangkit Listrik Tenaga Surya di Pulau Sembilan. Pelaksanaan tender ini telah dilakukan secara online dan telah mengundang banyak penyedia yang punya kualifikasi.

Salah satu dampak yang terjadi setelah tender PLTS berlangsung selain dengan terlaksananya proyek dengan baik adalah ditetapkannya Kuasa Pengguna Anggaran (KPA) sebagai tersangka karena telah menandatangani pencairan proyek (Syamsuddin, 2014). Kasus ini menyebabkan peneliti merasa penasaran apakah ini salah satu efek keterbukaan informasi tender melalui media online atau bukan.

Hal lain yang menjadi pertanyaan adalah pada tender PLTS yang dilakukan tahun 2013, proses pengadaan berlangsung normal sesuai dengan aturan. Nilai anggaran sebesar 3.02 Milyar dan masuk dalam kategori pengadaan konstruksi. Namun ada tender 
PLTS yang diulang hingga tiga kali dan dalam pengumumannya mengundang penyedia yang disebut namanya dan tidak terbuka untuk semua.

Berdasarkan paparan di atas maka penulis tertarik untuk meneliti bagaimana Unit Layanan Pengadaan, Penyedia Barang dan Jasa, Masyarakat serta Auditor memanfaatkan media online dalam pelaksanaan tender dengan mengambil contoh pada pengadaan PLTS di Pulau Sembilan Kabupaten Sinjai sehingga memilih judul "Penggunaan Media Online dalam Lelang Proyek Pembangkit Listrik Tenaga Surya di Pulau Sembilan Kabupaten Sinjai". Penelitian ini bertujuan untuk menggambarkan pelaksanaan lelang secara online di Kabupaten Sinjai dengan mengambil contoh lelang PLTS serta memaparkan transparansi yang diciptakan.

\section{BAHAN DAN METODE}

\section{Lokasi dan Rancangan Penelitian}

Penelitian dilakukan di Dinas

Komunikasi Informatika Kebudayaan dan Kepariwisataan Kabupaten Sinjai sebagai penyelenggara media online serta di Kecamatan Pulau Sembilan. Rancangan (desain) yang digunakan dalam penelitian ini adalah studi kasus dengan mengangkat tema penggunaan media online dalam tender PLTS di Pulau Sembilan Kabupaten Sinjai. Penelitian ini menjelaskan penggunaan teknologi informasi dalam mendukung open government dan open data informasi publik.

\section{Sumber Data}

Data primer yang berasal dari informan yang dipilih secara purposive untuk diwawancarai dan data sekunder yang berasal dari dokumen-dokumen serta aplikasi media online yang diakses. Informan yang diwawancarai berjumlah 23 orang yang terbagi dari 7 (tujuh) kelompok yaitu pengelola media, LSM, pokja ULP, penyedia, auditor, masyarakat dan PPK. Dokumen yang diteliti berbentuk tulisan, gambar, surat-surat penting, surat keputusan, peraturan daerah, peraturan bupati, dan dokumen lain yang berhubungan dengan lelang online PLTS di Sinjai.

\section{Metode Pengumpulan Data}

Pengumpulan data pada penelitian ini dilakukan dengan Triangulasi yaitu Observasi langsung ke media online yang menjadi obyek penelitian, observasi dilakukan dengan cara observasi terus terang atau tersamar. Peneliti memperkenalkan diri pada tim LPSE dan pihak pengguna media online bahwa sedang melakukan penelitian untuk kemudian melakukan wawancara mendalam kepada pihak-pihak yang menggunaakan media tersebut dan dokumentasi yang tersedia. Peneliti juga mengakses semua data dari web yang tersedia, mengambil gambar kegiatan, membuat surat permohonan agar diberikan akses ke dokumen-dokumen yang bisa membantu dalam penelitian ini. Semua informasi dari studi dokumentasi ini termasuk data sekunder yang non manusia.

\section{Analisis Data}

Data yang didapatkan dianalisa sesuai yang ditulis Miles \& Huberman dalam Sugiyono (2012), yaitu aktivitas dalam analisis data kualitatif dilakukan secara interaktif dan berlangsung terus-menerus sampai tuntas, sehingga datanya sudah jenuh. Seteleh semua data direduksi maka data kemudian ditampilkan. Dalam hal ini Miles \& Huberman menyatakan, yang paling digunakan untuk menyajikan data dalam penelitian kualitatif adalah dengan teks yang bersifat naratif.

\section{HASIL PENELITIAN}

Pemkab Sinjai melalui Dinas Kominfobudpar telah menyediakan sarana untuk memudahkan penduduknya mengakses internet terutama yang ada di daerah kota. Telah tersedia banyak titik akses internet di tempat-tempat publik.

Kebutuhan penggunaan media online dalam pelayanan masyarakat semakin dibutuhkan sehingga Tim website Sinjai dibentuk dengan mengacu pada Inpres No. 3 Tahun 2003. Begitu pula dengan kebutuhan akan kemudahan dalam bidang pengadaan barang dan jasa sehingga berdasarkan Perpres 54 Tahun 2010, Bupati mengeluarkan Perbup No. 7 Tahun 2011 tentang LPSE (Layanan Pengadaan Secara Elektronik). Tim Website dan Tim LPSE pun dibentuk dan personilnya ditunjuk berdasarkan SK Bupati Sinjai yang selalu diperbaharui tiap tahun. Tim-tim ini yang mengoperasikan media online tersebut. Pokja ULP yang juga dibentuk berdasarkan SK Bupati bekerja sebagai panitia lelang yang menyelenggarakan proses lelang bersama dengan Pejabat Pembuat Komitmen. SK 
Bupati tentang Pokja ini juga diperbaharui tiap tahun.

Media online yang digunakan dalam pelaksanaan lelang PLTS ini bisa dilihat pada tautan di situs resmi www.sinjaikab.go.id yang menyediakan informasi lelang PLTS dan hasil yang diperoleh. Dari situs tersebut akan terlihat bahwa situs resmi Sinjai menyediakan informasi tentang lelang secara umum, proses lelang dilakukan melalui situs LPSE Sinjai http://lpse. PLTS ini. Tabel 1 memberikan gambaran tentang transparansi yang diciptakan hasil wawancara dengan responden.

\section{PEMBAHASAN}

Penelitian ini memperlihatkan bahwa pengadaan PLTS di Pemkab Sinjai dilakukan menggunakan media online. New Media atau media online itu sendiri didefinisikan sebagai produk dari komunikasi yang termediasi teknologi yang terdapat bersama dengan komputer digital (Creeber \& Martin, 2009). Definisi lain media online adalah media yang di dalamnya terdiri dari gabungan berbagai elemen. Itu artinya terdapat konvergensi media di dalamnya, dimana beberapa media dijadikan satu (Lievrouw \& Livingstone, 2006). New Media merupakan media yang menggunakan internet, media online berbasis teknologi, berkarakter fleksibel, berpotensi interaktif dan dapat berfungsi secara privat maupun secara public (Mondry, 2008).

Pemerintah Kabupaten Sinjai telah menyediakan infrastruktur yang memadai untuk mengakses internet dengan beberapa titik wifi hotspot seperti di Gojeng, Hutan Kota Demma, kantor Dinas Kominfo dan lapangan nasional. Pertumbuhan kafe-kafe yang menyediakan akses internet gratis juga semakin banyak. Penyedia konten pun semakin beragam.

Komponen dari new media terdiri dari 3 unsur yaitu pembuat, penyalur dan pemakai dari new media itu sendiri. Pemkab Sinjai telah memanfaatkan internet untuk menyediakan media yang bisa menjadi tempat interaksi antara pemerintah dan masyarakat secara umum.

Pemerintah Kabupaten Sinjai telah menjadi unsur pembuat informasi sebagai komunikator menyampaikan pesan pembangunan pada masyarakat. Dinas Komunikasi dan Informatika yang menjadi pelaksana tugas kemudian menyediakan sebuah media online yang akan menjadi saluran pesan-pesan yang akan disampaikan dan adanya pengguna informasi atau komunikan yang kemudian bisa mengakses media tersebut sesuai dengan kebutuhannya.

Website Sinjai yang telah ada sejak berlakunya Inpres No. 3 Tahun 2003 tentang e-government telah berusaha menyediakan berbagai informasi dari pemerintah yang bersifat terbuka kepada masyarakat.

Proses lelang online melalui Perpres No. 54 tahun 2010 pun dijadikan acuan dalam penyusunan Perbup tentang LPSE dan menjadi dasar terbentuknya tim LPSE dan penyediaan infrastrukturnya.

Salah satu karakteristik new media adalah interaktifitas menurut McQuail dalam Cangara (2014), ada interaksi / feedback antara penyedia informasi dan penerima informasi. Proses komunikasi terjadi dengan lancar. Website Sinjai menyediakan tempat untuk melakukan diskusi tentang suatu permasalahan yang ada pada masyarakat dan pemerintah bisa memberikan jawaban. Proses lelang online pun seperti itu, ada interaksi antara pokja dan penyedia.

Teori Uses and Gratifications (kegunaan dan kepuasan) menunjukkan bahwa yang menjadi permasalahan utama adalah bagaimana media memenuhi kebutuhan pribadi dan sosial khalayak yang menjadi pengguna media. Inti kajiannya adalah pada khalayak yang aktif yang sengaja memilih dan menggunakan media untuk mencapai tujuan khusus, yaitu pemuas kebutuhan hidupnya (Effendy, 2005). Khalayak aktif ini juga dipertegas oleh asumsi teori ini oleh Katz, Blumer dan Gurevitch (Bahfiarti, 2012)

Penyedia, Auditor, LSM dan pokja ULP adalah khalayak aktif yang menggunakan media sesuai dengan kebutuhan mereka akan informasi didasarkan dorongan mendapatkan pengetahuan dan terlibat aktif dalam mengawasi.

Teori information seeking, Donohew \& Tipton (1973), yang menjelaskan tentang pencarian, penghindaran, dan memproses informasi, disebut memiliki akar dari pemikiran psikologi sosial tentang kesesuaian sikap. Salah satu asumsi utamanya adalah bahwa orang cenderung untuk menghindari informasi yang tidak sesuai dengan image of reality-nya karena terasa membahayakan.

Masyarakat pulau sembilan yang ada 
dalam isolasi laut serta kesulitan dalam listrik, pencarian informasinya masih menunggu dari dinas atau instansi terkait serta dari pejabat desa yang ada disekitar mereka. Belum ada yang memanfaatkan media online yang disediakan oleh pemerintah Kabupaten Sinjai yang senantiasa memberikan informasi pembangunan dan kegiatan lelang walaupun kegiatan proyek itu berada disekitar mereka.

Berbeda dengan para informan dari Kopel, Inspektorat, Penyedia dan Pokja ULP yang telah diwawancarai. Mereka ini telah berusaha untuk mengisi kekosongan dari ketidaktahuan informasi dengan mengakses media online yang tersedia. Mereka memanfaatkan teknologi internet yang sudah semakin mudah untuk diakses dari berbagai macam perangkat untuk memenuhi kebutuhan mereka akan informasi yang ingin diketahuinya.

Penyedia aktif membuka media online khususnya SPSE karena ada informasi lelang yang akan diikuti ataupun sedang proses sesuai jadwal yang terprogram oleh pokja ULP. LSM aktif menggunakan media online website Sinjai dan SPSE untuk melihat pengumuman lelang dan pencarian informasi yang berkaitan dengan pembangunan di Sinjai. Auditor juga menggunakan media SPSE untuk melakukan audit jika ada perintah pimpinan dan akan dibuatkan akun khusus untuk mengakses semua proses lelang dari awal hingga akhir.

Kepuasan yang dicari (gratifikasi sought) dengan penggunaan media oleh McQuail \& Karen (1998) sesuai dengan motif masing-masing. Motif gratifikasi informasi yang menjadikan semua pihak yang punya kepentingan terhadap informasi lelang akan berusaha memenuhi kepuasan akan informasi yang dicarinya.

Kopel sebagai LSM sudah aktif melakukan pemantauan proyek-proyek pemerintah Kab. Sinjai sejak tahun 2011 selalu berusaha memenuhi kebutuhan informasi akan lelang-lelang yang dilakukan oleh pemerintah mulai dari perencanaan hingga perencanaan.

Motif lainnya yang bisa kita lihat dari Kopel, Auditor, Penyedia dan Pokja ULP ini adalah adalah motif identitas personal dan dorongan untuk memperkuat nilai-nilai pribadi, memperkuat kredibilitas, stabilitas dan status. Mereka semua mengakses informasi menyesuaikan dengan identitas masing-masing serta status yang disandangnya.
Adapun motif gratifikasi dengan interaksi sosial berkaitan dengan interaksi orang untuk berinteraksi dengan orang lain, mempertahankan norma-norma sosial dan menjalankan peran sosial. Penyedia, Auditor dan LSM berusaha untuk bisa berinteraksi dengan pokja ULP melalui sistem SPSE. Begitu pula dengan PPK. Pihak penyedia media online dari tim website Sinjai dan LPSE telah menyediakan fitur pada website untuk melakukan interaksi ini serta penyediaan helpdesk di LPSE.

Kepuasan yang diperoleh (gratifikasi obtained) para informan yang punya motif tentang kepuasan yang dicari (gratifikasi sought) bisa kita lihat dari hasil wawancara bahwa informan dari Kopel mengaku dengan perkembangan teknologi sekarang ini dan ketersediaan media oleh pemkab Sinjai, datadata yang tersedia dan terpublikasi belum menyentuh kebutuhan mereka.

Informan dari inspektorat Sinjai belum bisa mengakses semua tahapan lelang karena belum ada perintah dari pimpinan walaupun sudah sering mendapatkan informasi bahwa terkadang ada permainan antara panitia lelang dan penyedia barang jasa.

Beda dengan informan yang memang memanfaatkan media tersebut untuk memberikan informasi dan melaksanakan lelang. Pokja ULP sangat menyentuh kebutuhan mereka, begitu juga dengan para penyedia barang dan jasa yang ikut dalam proses lelang.

Jadi kepuasan yang didapatkan oleh para informan ini masih belum sesuai dengan kepuasan yang mereka dapatkan dari media online yang tersedia. Sistem telah diusahakan oleh tim web dan LPSE bekerja dengan sangat baik tapi konten yang diberikan terutama yang berkaitan dengan masalah transparansi pada proses lelang antara pengumuman lelang dan penentuan pemenang masih belum memenuhi keinginan dari para pencari informasi.

Walaupun semua informasi lelang sudah terpenuhi sesuai dengan keinginan dari penyedia termasuk cara berinteraksi sejak penjelasan lelang hingga proses sanggahan tapi tetap saja ada ketidakpuasan yang diperoleh. Gangguan informasi yang para penyedia ini biasa dapatkan berasal dari sistem dan koneksi internet. Waktu yang terprogram sesuai dengan tahapan lelang itu memang harus betul-betul diperhatikan baik oleh 
penyedia maupun oleh pokja ULP sebagai perencana waktu dan tahapan lelang.

\section{KESIMPULAN DAN SARAN}

Kami menyimpulkan bahwa Pemkab Sinjai telah memanfaatkan media online yang disiapkan oleh tim website Sinjai dan tim Layanan Pengadaaan Secara Elektronik untuk pelaksanaan lelang PLTS sejak penyediaan Rencana Umum Pengadaan hingga pelaksanaan lelang dan penetuan pemenang walaupun belum mendukung sepenuhnya transparansi dengan masih adanya tahapantahapan lelang yang belum bisa dilihat secara terbuka. Sistem Pengadaan Secara Elektronik yang digunakan pada proses lelang di Pemkab Sinjai perlu untuk selalu diupdate ke versi terbaru dan tim LPSE harus terus berkordinasi ke LKPP untuk bisa memberikan masukan agar sistem lelang online ini menjadi semakin terbuka dan transparan dengan membuka proses lelang terutama pada laporan akhir yang dibuat oleh pokja ULP. Tim website Sinjai perlu untuk terus memperbaharui informasi lelang dan keuangan terutama yang berkaitan APBD dan penyaluran dana pembangunan yang telah terealisasi.

\section{DAFTAR PUSTAKA}

Abrar A.N. (2003). Teknologi Komunikasi Perspektif Ilmu Komunikasi. LESFI. Yogyakarta .

Bahfiarti. (2012). Buku Ajar Dasar-Dasar Teori Komunikasi, Makassar, Universitas Hasanuddin

Cangara. (2014). Pengantar Ilmu Komunikasi. P.T. RajaGrafindo Persada, Jakarta

Creeber G. \& Martin R. (2009). Digital Cultures: Understanding New Media, Berkshire-England: Open University Press.

Donohew L. \& Tipton L. (1973). A Conceptual Model Information
Seeking, Avoiding and Processing, New Holder for Communication Research. Sage Publication London

Effendi O.U. (2005). Komunikasi dan Modernisasi, Mandar Maju : Bandung

Lievrouw L. A. \& Livingstone. (2006). Handbook of New Media. Los Angeles, London, New Delhi, Singapore, Washington DC: Sage Publications Ltd

Mardiasmo. (2004). Perwujudan Transparansi dan Akuntabilitas Publik Melalui Akuntansi Sektor Publik : Suatu Sarana Good Governance. Andi Yogyakarta

McQuail D. \& Karen S. (1998). Media Policy: convergence, concentration and commerce. Sage, London

Mondry. (2008). Pemahaman Teori dan Praktik Jurnalistik. Bogor: Ghalia Indonesia

Sugiyono. (2012). Metode Penelitian Kuantitatif, Kualitatif dan $R \& D$. Alfabeta: Bandung.

Syamsuddin. (2014). Kadis ESDM Sinjai

Ditahan, Tindakan Kejari di

Pertanyakan. Diakses 20 Juni 2016.

Available from:

http://rakyatsulsel.com/kadis-esdmsinjai-ditahan-tindakan-kejari-dipertanyakan.html 
Tabel 1. Ringkasan hasil wawancara responden Mei-Juni 2016 tentang Transparansi yang diciptakan melalui Penggunaan Media Online dalam Proses Lelang PLTS Pulau Sembilan

\begin{tabular}{|c|c|c|}
\hline No. & Kategori & Hasil wawancara \\
\hline 1 & Transparansi yang diciptakan & $\begin{array}{l}\text { 1. Masyarakat belum bisa melihat proses yang } \\
\text { berada dalam ranah panitia } \\
\text { 2. Website belum menampilkan informasi publik } \\
\text { sedangkan LPSE masih memberikan } \\
\text { gambaran umum awal dan akhir proyek } \\
\text { 3. Proses antara pokja dan penyedia hanya bisa } \\
\text { dilihat oleh auditor yang memiliki akun ke } \\
\text { SPSE } \\
\text { 4. Proses evaluasi antara pengumuman dan } \\
\text { penentuan pemenang masih tertutup. }\end{array}$ \\
\hline 2 & Faktor Sumber Daya Manusia & $\begin{array}{l}\text { 1. Tim LPSE telah berulang kali ikut pelatihan } \\
\text { di LKPP dan mengikuti setiap kegiatan- } \\
\text { kegiatan LPSE baik di provinsi maupun di } \\
\text { LKPP. } \\
\text { 2. Anggota Pokja sudah bekerja profesional } \\
\text { sesuai aturan dan SOP walaupun banyak } \\
\text { tekanan dari berbagai pihak yang } \\
\text { berkepentingan terhadap lelang PLTS ini, } \\
\text { bahkan melakukan intervensi pada pokja. } \\
\text { 3. Pernah ada intervensi dari DPRD sehingga } \\
\text { banyak anggota pokja yang minta } \\
\text { mengundurkan diri. }\end{array}$ \\
\hline
\end{tabular}

